\title{
Mathematical Theory of Reliability and Aging: A Little Bit of History and the State of Art
}

\author{
Vitaly K Koltover* \\ Institute of Problems of Chemical Physics, Moscow Region, Russia \\ *Corresponding author: Vitaly K Koltover, Institute of Problems of Chemical Physics, RAS, Chernogolovka, Moscow Region, Russia \\ Submission: 制 February 26, 2018; Published: 阱 March 20, 2018
}

\section{Editorial}

In engineering, reliability is defined as the ability of a device to perform the preset function for the given time under the given conditions. The foundations of mathematical theory of reliability were laid in the 1950s due to the needs of aeronautic machinery, electronics, problems of communication and management, etc. [13]. Like in engineering, each and all biological systems are devices constructed to perform the preset functions according to the information planes, i.e. - the genetic programs. Biological constructs perform their functions in the presence of a great number of random factors which disturb all functional strata, starting from the molecular level of organization and to ecosystems inclusive. Therefore, similarly to technical devices, biological constructs are not perfectly reliable in operation, i.e. - for each and every device normal acts of operations alternate with stochastic (random) malfunctions or failures.

The problem of reliability of biological systems was first put forward by D. Grodzinsky and his collaborators [4]. The regular conferences on reliability of biological systems, starting from the first one in 1975 in Kiev, former USSR, have given a strong impetus to research in this direction [5-17]. Thus, located at the cross-roads of Western Europe and the Orient, Kiev has spurred the studies on reliability ("robustness") of biological systems. It confirms the old saying of the Middle Ages that "Teaching comes from Kiev." Not long ago, a new wave of analogous research has been spurred under the style of "biological robustness", see [18-21] and references therein.

The problem of reliability has direct bonds to the problems of aging. The systems reliability approach, which was developed in our papers, is based on the simple general postulates. First, all biological constructs are designed in keeping with genetic programs in order to perform the preset functions. Second, we believe that all constructs operate with limited reliability, namely, for each and every biological device normal operation acts alternate with accidental malfunctions (recurrent failures). Third, preventive maintenance, i.e., the timely replacement or prophylaxis of unreliable functional elements - metabolic turnover that follows a pattern preset in the genome, is the main line of assuring high systems reliability. Forth, there are a finite number of critical elements of the highest hierarchic level which perform the supervisory functions over the preventive maintenance ("the power structure"). And, five, the "supervisors" also operate with the limited, genetically preset, reliability. On this systems reliability basis, the universal features of aging of living organisms, such as the exponential growth of mortality rate with time and the correlation of longevity with species-specific resting metabolism, are naturally explained. From the reliability point of view, aging occurs as the inevitable consequence of the genetically preset deficiency in reliability of biomolecular constructs while the mitochondrial free-radical redox-timer, located in the specialized cells of central nervous system, serves as the effective stochastic mechanism of realization of the aging program. The longevity of human brain could reach 250 years should the antioxidant enzyme defense against the free-radical failures be perfect [21-23].

Furthermore, the systems reliability approach was successfully applied to revise the problem of antioxidant defense. Some antioxidants, synthetic and natural ones, extend lifespans of animals when added to food or drinking water. However, the rate constants and concentrations of the so-called antioxidants are small to compete with the antioxidant enzymes for reactive oxygen species (ROS). The antioxidants provide a preventive protection against ROS, i.e. - prophylactic maintenance via the organism's neuro-hormonal system and/or microbiota (see refs. in [24]). Thus, the systems reliability approach serves as heuristic methodology in searching realistic mechanisms of aging and anti-aging therapy.

\section{References}

1. Bazovsky I (1961) Reliability. Theory and Practice. Prentice-Hall, London.

2. Lloyd DK, Lipov M (1962) Reliability: Management, Methods and Mathematics. Prentice Hall, New Jersey.

3. Gnedenko BV, Belyaev, Yu K, Soloviev AD (1965) Mathematical Methods in Theory of Reliability:: Nauka, Moscow, Russian.

4. Grodzinsky DM, Vojtenko VP, Kutlakhmedov YA, Koltover VK (1987) Reliability and Aging of Biological Systems. Kiev. Naukova Dumka, Russian.

5. Koltover VK, Kutlakhmedov YA, Afanaseva EL (1980) Recovery of cells from radiation-induced damages in the presence of antioxidants and the reliability of biological systems. Doklady Biophysics 254(3): 159-161. 
6. Koltover VK (1981) Reliability of enzymatic protection of a cell against superoxide radicals and the aging. Doklady Biophysics (Doklady Akad Nauk SSSR) 256(1): 3-5.

7. Doubal S (1982) Theory of reliability, biological systems and aging. Mech Ageing Develop 18(4): 339-353.

8. Witten MA (1983) Return to time, cells, systems and aging: Rethinking the concept of senescence in mammalian organisms. Mech Ageing and Develop 21(1): 69-81.

9. Koltover VK (1988) Reliability of Electron-Transport Membranes and the Role of Oxygen Anion-Radicals in Aging (Doctoral Dissertation in Biophysics). Kiev (fSU): A Bogomolets Institute of Physiology. Acad Sci of Ukraine SSR, p. 351.

10. Koltover VK (1992) Free radical theory of aging: View against the reliability theory. In: Emerit I, Chance B. (Eds.), Free Radicals and Aging. Birkhauser, pp. 11-19.

11. Koltover VK (1997) Reliability concept as a trend in biophysics of aging. J Theor Biol 184(2): 157-163.

12. Gavrilov LA, Gavrilova NS (2001) The reliability theory of aging and longevity. J Theor Biol 213(4): 527-545.

13. Finkelstein M (2005) On some reliability approaches to human aging. Int J Reliability, Quality Safety Eng 12(4): 337-346.

14. Steinsalt D, Goldwasser L (2006) Ageing and total quality management: Extending the reliability metaphor for longevity. Evolutionary Ecology Res 8: 1445-1459.

15. Kutlakhmedov Yu, Korogodin V, Rodina V, Pchelovskaya S (2006) Radiocapacity: characteristic of stability and reliability of biota in ecosystems. In: Cigna AA, Durante M (Eds.), Radiation Risk Estimates in Normal and Emergency Situations. Dordrecht: Springer, NATO Security Trough Science Series B: Physics and Biophysics 9: 185-195.
16. Dimitrov B (2010) Ages in reliability and biosystems: interpretations, control, and applications. In: Rykov VV, Balakrishnan N, Nikulin MS (Eds.), Mathematical and Statistical Models and Methods in Reliability Statistics for Industry and Technology. Dordrecht: Springe 3: 317-334.

17. Koltover VK (2014) Theory of reliability in systems biology: aging versus reliability. In: Valente AX Sarkar A, Gao Y (Eds.), Recent Advances in Systems Biology Research. Nova Science Publishers, pp. 109-130.

18. Kitano H (2004) Biological robustness. Nat Rev Genet 5(11): 826-837.

19. Larhlimi A, Blachon S, Selbig J, Nikoloski Z (2011) Robustness of metabolic networks: A review of existing definitions. Biosystems 106(1): 1-8.

20. Kriete A (2013) Robustness and aging - a systems-level perspective. Biosystems 112(1): 37-48.

21. Koltover VK (2018) Mathematical theory of reliability and biological robustness: reliable systems from unreliable elements. In: Casanova $M$ (Ed.), Focus on Systems Theory Research. Nova Science Publishers, New York.

22. Koltover VK (2016) Mathematical theory of reliability and aging: Teaching comes from Kiev. In: Frenkel I, Lisnianski A (Eds.), Proceedings of the Second International Symposium on Stochastic Models in Reliability Engineering, Life Science and Operations Management. IEEE CPS, New York, pp. 386-392.

23. Koltover VK (2017) Free radical timer of aging: from chemistry of free radicals to systems theory of reliability. Curr Aging Sci 10(1): 12-17.

24. Koltover VK (2017) Antioxidant therapy of aging: from free radical chemistry to systems theory of reliability. In: Vaiserman AM (Ed.), AntiAging Drugs: from Basic Research to Clinical Practice. Royal Society of Chemistry Publishing, Cambridge, UK, pp. 183-204.
Creative Commons Attribution 4.0

International License

For possible submissions Click Here

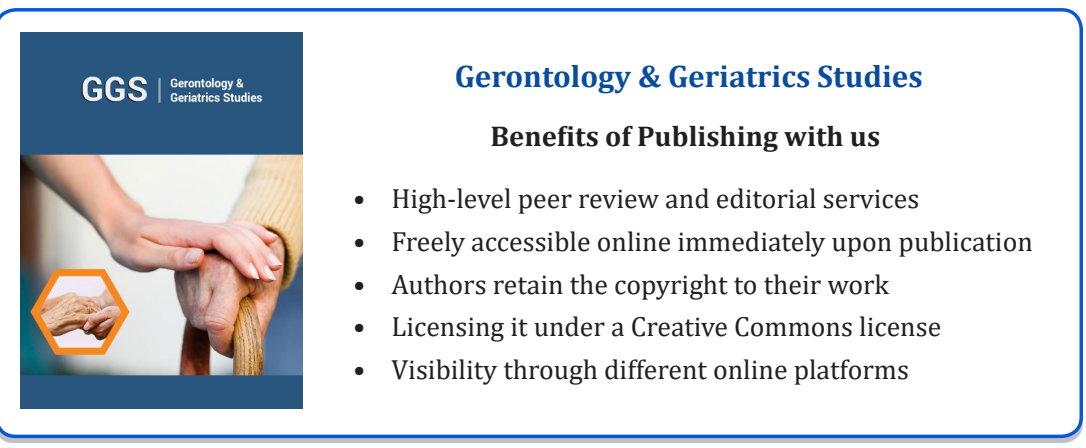

